\title{
The results of the structure optimization of the vehicles fleet and container park of the specialized motor transportation enterprise
}

\author{
Igor Lyubimov ${ }^{1 *}$, Alexey Melnikov ${ }^{1}$, and Konstantin Manayev ${ }^{1}$ \\ ${ }^{1}$ Orenburg State University, 13 Prospect Pobedy, Orenburg, 460018, Russia
}

\begin{abstract}
The article leads to the results of experimental observations which purpose was the adequacy assessment of the elaborated theoretical provisions, namely the interrelation of the fleet structure and the performance indicators of its functioning. The experimental study was carried out in several steps according to the developed methodology.
\end{abstract}

\section{Introduction}

Functioning of any settlement is followed by the formation of the solid domestic waste (SDW), where normal conditions of the accommodation in the settlement (a sanitary and hygienic, ecological, social and economic situation) are in a considerable measure defined by timely SDW collecting and removing. The process of SDW collecting and removing which number depends on a set of factors (population density, seasonality, etc.) has to be carried out with the minimum expenses of labor and material resources. The questions of the rational structure formation for the rolling stock (motor transport) for SDW removing and the modes of its work, the correct choice of characteristics of SDW concentration means (the containers park) and the placement of these means on the settlement territories are of current interest in connection with a considerable variation of SDW volumes in places of their formation and concentration.

\section{Material and methods}

As a result we have the formation of the route and logistic scheme meeting social needs of the settlement and providing its sanitary and epidemiologic and ecological indicators [1416].

There are certain restrictions connected with the strategy development determined by the enterprise and the interaction scheme with customers at the organization of transport work. According to the developed mathematical model [1-7], the efficiency improvement at functioning of the motor transportation enterprise is directed to the costs cutting for the vehicles operation, and that most, to the cost reduction for the unit of transport operation.

\footnotetext{
*Corresponding author: 1yubimovii@gmail.com
} 


\section{Theory}

The developed model allows to optimize the structure of vehicles and containers fleets for collecting and removing of solid domestic waste providing the production implementation with the minimum operational expenses.

The mathematical model is the following:

$$
\begin{gathered}
F=\frac{\sum_{i=1}^{n} N_{i} \cdot a_{i}+\sum_{j=1}^{u} C_{j} \cdot b_{j}}{\sum_{i=1}^{n} \sum_{j=1}^{u} \frac{T_{w} q_{i} N_{i} D_{w y j}}{l_{e l}}+t_{1 u j} C_{j}} \rightarrow \mathrm{min}, \\
\sum_{i=1}^{n} \sum_{j=1}^{u} \frac{T_{w} q_{i} N_{i} D_{w y j}}{l_{e l}}+t_{1 u j} C_{j} \\
\beta V_{t} \\
N_{j} \geq 0 ; K_{j} \geq 0 ; \\
a_{i}=\operatorname{const} ; b_{j}=\text { const } \\
i=1 . . . n ; j=1 . . . u \\
\Delta \leq[\Delta] .
\end{gathered}
$$

where $F$ - cost value of SDW transportation, rub./ $\mathrm{m}^{3} ; N_{i}$ - the number of specialized vehicles of i-model, un.; $C_{j}$ - the containers number of $j$-type, un., $T_{w}-$ time at work, h; $q_{i}-$ the vehicle capacity of i-type, $\mathrm{m}^{3} ; l_{e l}$ - length of the trip with the load, $\mathrm{km} ; \beta$ - the coefficient of the mileage usage; $V_{t}$ - the technical speed of the vehicle, $\mathrm{km} / \mathrm{h} ; t_{l u j}$ - the duration of loading and unloading works using $\mathrm{j}$-container fleet, $\mathrm{h} ; t_{l c j}$ - the duration of unloading for one $j$-container; $D_{w y j}$ - the number of days in a year for the rolling stock work on the route using $\mathrm{j}$-container fleet.

The time spent of the vehicle work and the technical speed of the vehicle are assumed as unchangeable sizes $[6,8-10]$ in $F$ calculations for the offered model.

The motor transportation enterprise LLC "MC "Spetsavtokhozyaystvo' was chosen as the research object. The activities of the motor transportation enterprise LLC "MC "Spetsavtokhozyaystvo" consist in high-quality and timely requirements satisfaction in collecting and removing of solid domestic waste (SDW). The rolling stock of LLC "MC "Spetsavtokhozyaystvo" consists of cars, trucks and specialized trucks. The branded distribution of the rolling stock of LLC "MC "Spetsavtokhozyaystvo" by years is presented in figure 1 .

The activities analysis of LLC "Managing company "Spetsavtokhozyaystvo" is made from 2010 to 2015 . Figure 2 shows the dynamics of volume for SDW removing, $\mathrm{m}^{3}$, during the researched period.

For the analysis of the production business activities of LLC "Managing Company "Spetsavtokhozyaystvo" the financial and economic information of the enterprise from 2010 to 2015 was considered. In connection therewith the cost value of collecting and removing of $1 \mathrm{~m}^{3}$ of SDW is taken as the parameter for the optimization in selecting the cost of the transport transaction unit $[1,3,5-8]$. 

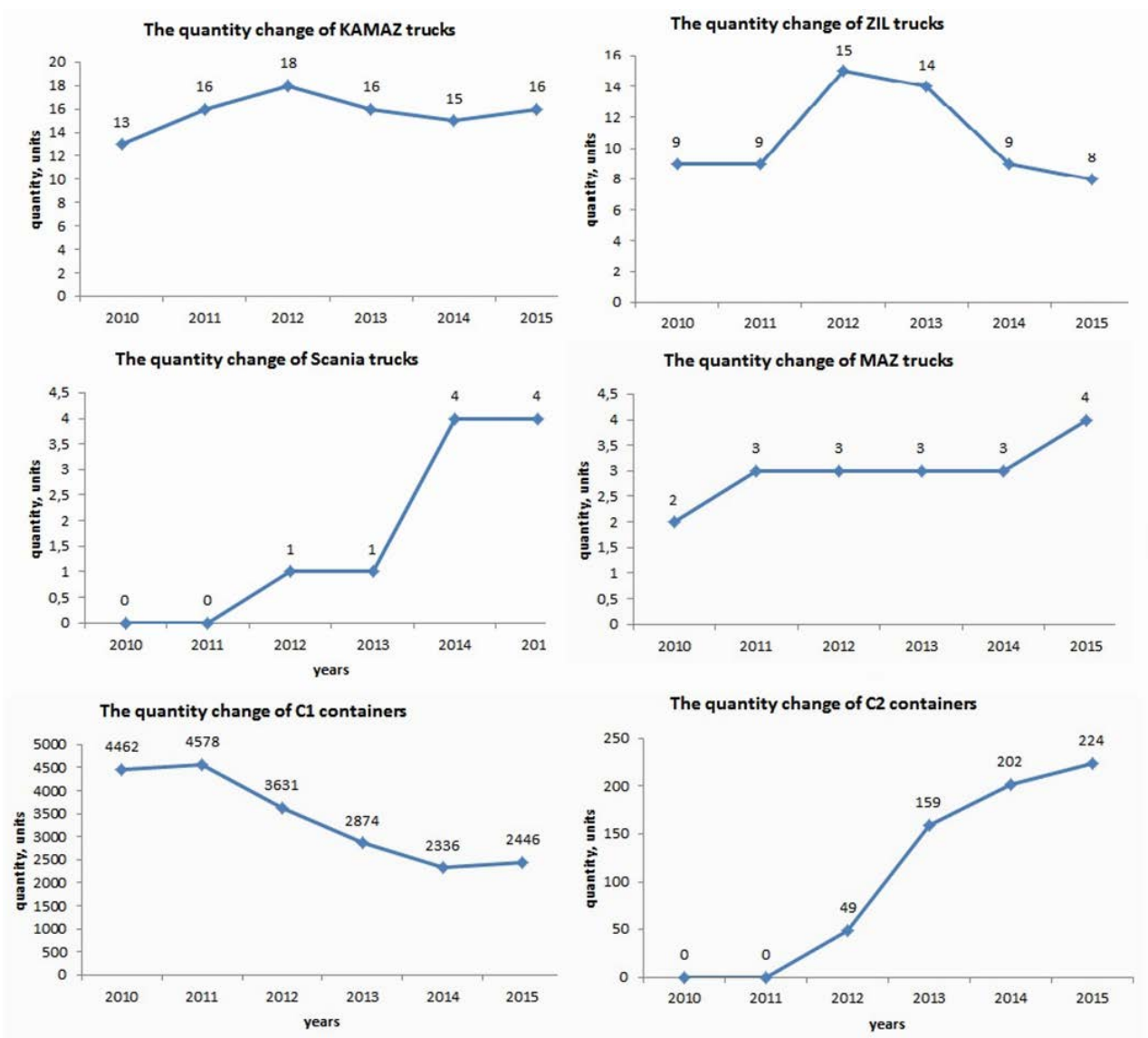

Fig. 1. The change in the structure of the vehicles and containers fleet.

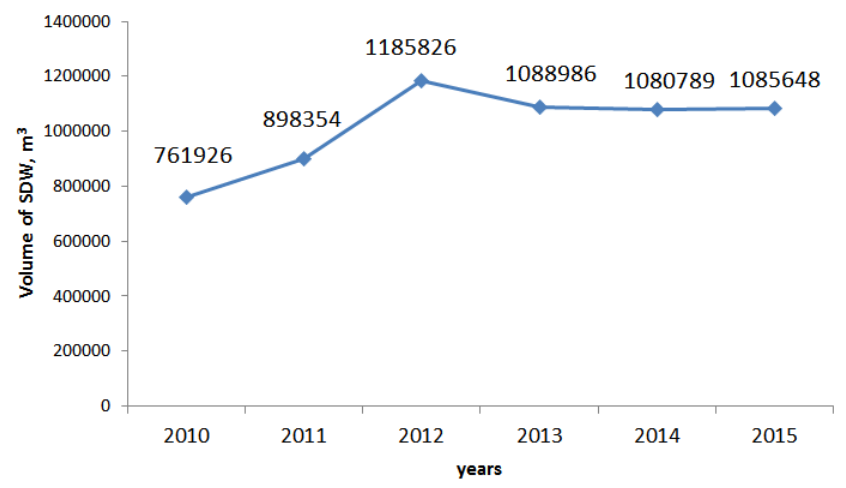

Fig. 2. The dynamics of volume for SDW removing in LLC "Managing company "Spetsavtokhozyaystvo".

In fig. 3 the cost dynamics of collecting and removing of SDW for $2010-2015$ is provided. 


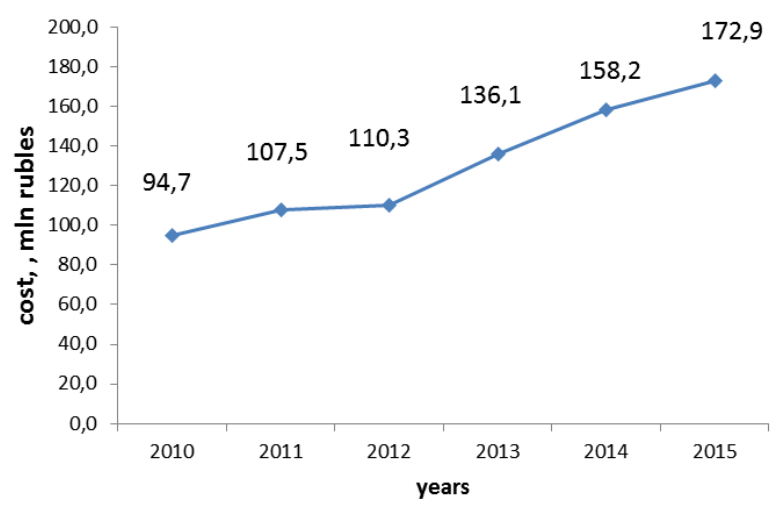

Fig. 3. The cost dynamics of collecting and removing of SDW

As evident from figure 3, the costs for transport work performance grow during all researched period.

Respectively the cost of the transport transaction unit also increases (fig. 4).

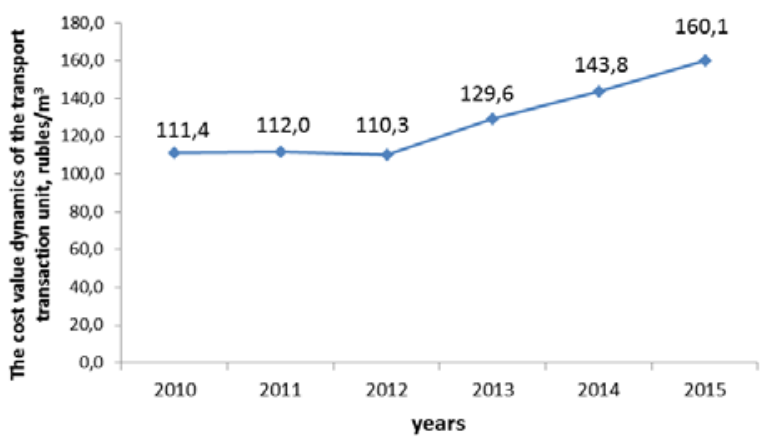

Fig. 4. The cost value dynamics of the transport transaction unit

The experimental examination of the developed theoretical provisions is carried out only on groups of the specialized rolling stock performing the SDW collection by means of containers. Other types of vehicles in further researches weren't considered in view of the limited contribution both to the SDW volume and to the total operating costs.

As a result of the calculation of the basic data matrix by means of the "Statistica" program the coefficients values of the regression model provided by dependence (2) are received:

$$
F=188,8-0,0179 \cdot N_{1}+0,9609 \cdot N_{2}+3,378 \cdot N_{3}-1,5374 \cdot N_{4}-0,0064 \cdot C_{1}-0,1196 \cdot C_{2},
$$

where $N_{1} \ldots N_{i}$ - number of vehicles in $i$-group; $C_{1} \ldots C_{j}$ - number of containers in $j$ - group.

According to the developed model and the algorithm, the choice of the rational structure of the vehicles and container fleet of the specialized motor transportation enterprise is made according to the results of the experimental study (received regression model). According to the coefficients values of the regression model the vehicles of $N_{2}$ and $N_{3}$ groups are subject to write-off. Thus, their quantity is equal in the corrected structure to 0 .

Taking into account the restriction on the actions cost for the adjustment of the vehicles and container fleet structure in 35 million rubles, the following information is accepted: 
The vehicles number in $N_{1}$ group (KAMAZ) - 18 units; in $N_{2}$ and $N_{3}$ groups (respectively ZIL and MAZ) - 0; in $N_{4}$ group (Scania) - 7 units.

The containers number of $C_{1}$ type -2015 units, the containers number of $C_{2}$ type -329 units.

The cost of transport transaction unit is reduced as a result of the research results implementation in practice of the production and economic activity of LLC "MC "Spetsavtokhozyaystvo" (fig. 5) [11-13].

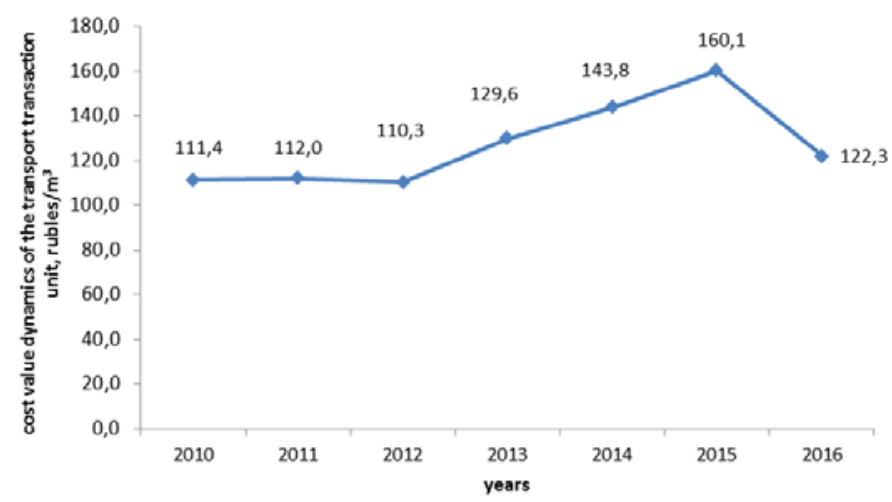

Fig. 5. The cost price dynamics of the transport operation unit of LLC "MC

"Spetsavtokhozyaystvo" after the implementation of the research results in the production business activity.

\section{Results and Discussion}

The developed algorithm, which differs in the multiple solution of the optimization problem taking into account the specific conditions of works on collecting and removing of solid domestic waste, allows to optimize the structure of the vehicles and container fleet on the basis of provisions of the sensitivity theory and allowing to estimate the influence of the rolling stock structure and the container fleet of the specialized motor transportation enterprise on the cost of the transport operation unit and the waste concentration means based on the technical and economic criterion.

As a result of the optimum structure formation of the rolling stock and the container fleet of the specialized motor transportation enterprise taking into account the efficiency criterion of functioning (on the example of the Orenburg enterprises) with the use of the developed technique the cost price of $1 \mathrm{~m}^{3}$ removing of solid domestic waste has decreased by $24,5 \%$ that has led to the costs reduction of operation on 21,7 million rubles a year.

\section{References}

1. Ye.V. Bondarenko, A.O. Zuyev, I.I. Lyubimov, K.I. Manayev, A.N. Mel'nikov, Infrastructure optimization of collection and removal of solid domestic wastes from the settlement territory, in: Vestnik of the Moscow automobile and road construction state technical university (MADI), Moscow, № 4. pp. 92a-96. (2011)

2. J. Bie, H. K. Lo, Stability and attraction domains of traffic equilibria in a day-to-day dynamical system formulation. Transportation Research Part B 44 (1), 90-107 (2010)

3. I.I. Lubimov, K.I. Manayev, A.N. Melnikov, Calculation of the quantity and the type of the vehicles for the specialized motor transport enterprise [Electronic resource]: 
certificate on the state registration of the computer program. Orenburg state university. - № 2016616975 from 01.07.2016 it is registered in the register of the computer programs 30.08.2016. - 1 p. (2016)

4. X. He, X. Guo, H. Liu, A link-based day to day traffic assignment model. Transportation Research Part B, 44 (4), 597 - 608 (2010).

5. B.G. Heydecker, Objectives, stimulus and feedback in signal control of road traffic. ITS Journal 8 (2), 63-76 (2004)

6. T-Y. Hu, H.S. Mahmassani, Day to day evolution of network flows under real-time information and reactive signal control. Transportation Research C, 5 (1), 51 - 69 (1997)

7. I.I. Lubimov, Improvement results of the solid domestic waste collecting and removing process from the settlement territory / I.I. Lubimov, K.I. Manayev, A.N. Melnikov // Progressive technologies in transport systems: materials collection of X International scientific and practical conference (April 24-26, 2013). - Kumertau: Kumertau town printing house. Pp. 345-350 (2013)

8. I.I. Lyubimov, K.I. Manayev, A.N. Mel'nikov, V.I. Rassokha, The algorithm development for the optimization of the rolling stock and container park at collecting and removing solid domestic wastes. Proceedings of the Tula state university. Technical sciences., Tula. № 4. pp. 174-182 (2011)

9. I.I. Lyubimov, K.I. Manayev, A.N. Mel'nikov, N.Z. Sultanov, Methodical fundamentals of the process optimization for collecting and removing solid domestic wastes. Intellect. Innovations. Investments, Orenburg. № 2. Pp. 35-40 (2011)

10. I.I. Lyubimov, N.Z. Sultanov, Theoretical bases of perfection transport system. Bulletin of the Orenburg State University, 10, 121-123 (2014)

11. I.I. Lyubimov, K.I. Manayev, A.N. Mel'nikov, N.Z. Sultanov, Specific function formation for the transport and logistic scheme optimization at collecting and removing of solid domestic wastes. Intellect. Innovations. Investments, Orenburg. № 3. pp. 5-8 (2011)

12. I.I. Lyubimov, A.N. Melnikov, N.A. Trubin The Control System Improvement of the City Motor Transportation Science Direct: Procedia Engineering. Volume 150. Pp. 1192-1199 (2016)

13. A.N. Melnikov, I.I. Lyubimov, K.I. Manayev Improvement of the Vehicles Fleet Structure of a Specialized Motor Transport Enterprise. Science Direct: Procedia Engineering. Volume 150. Pp. 1200-1208 (2016)

14. N.V. Vagapova, B.A. Portnikov, N.Z. Sultanov, I.I. Lyubimov, Functional processes management of city passenger transportation. Intellect. Innovations. Investments., Orenburg, № 2, Pp. 49-56 (2009)

15. P. Varaiya, Max pressure control of a network of signalised intersections. Transportation Research Part C, 177-195 (2013)

16. J. G. Wardrop, Some theoretical aspects of road traffic research. Proceedings of the Institute of Civil Engineers Part II, 1, 325-378 (1952) 